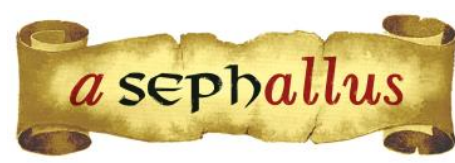

Revista aSEPHallus de Orientação Lacaniana

Núcleo Sephora de Pesquisa sobre o Moderno e o Contemporâneo

ISSN 1809 - $709 \mathrm{X}$

\title{
Impasses na aprendizagem e inibição intelectual ${ }^{1}$
}

Luciana Renata Moreira Fonseca

Orcid:0000-0002-5598-556X

Doutoranda e Mestre em Educação pela Universidade Federal de Minas Gerais / UFMG (Minas Gerais, Brasil) Graduada em Pedagogia pela Universidade Federal de Minas Gerais/ UFMG (Minas Gerais, Brasil) Funcionária pública da Prefeitura Municipal de Itabira/MG

e-mail: lurmfonseca@yahoo.com.br

Raquel Martins de Assis

Orcid:0000-0001-5248-1131

Doutora em Educação pela Universidade Federal de Minas Gerais/ UFMG (Minas Gerais, Brasil) Professora associada da Universidade Federal de Minas Gerais / UFMG (Minas Gerais, Brasil) e-mail: rmassis.ufmg@gmail.com

Ana Lydia Bezerra Santiago Orcid: 0000-0003-4405-6244

Doutora em Psicologia Clínica pela Universidade de São Paulo / USP (São Paulo, Brasil) Professora associada da Universidade Federal de Minas Gerais / UFMG (Minas Gerais, Brasil) e-mail: analydia.ebp@gmail.com

\begin{abstract}
Resumo
O presente artigo descreve os resultados de uma pesquisa-intervenção de orientação psicanalítica por meio do relato de um estudo de caso de um aluno do ensino fundamental de uma escola pública da rede estadual de ensino da cidade de Itabira-MG. O estudante enfrenta vários entraves na aprendizagem que dificultam sua alfabetização e seu processo de letramento. O caso visa demonstrar a contribuição de um dos instrumentos utilizados nessa pesquisa que é o diagnóstico clínico-pedagógico (DCP), cuja intervenção realiza a leitura daquilo que o menino ensina ao educador sobre sua subjetividade e a forma como suas particularidades podem interferir na relação com o saber. Os resultados obtidos na pesquisa permitiram perceber como a angústia de castração, os temores infantis e as fobias podem se constituir no fenômeno da inibição intelectual e comprometer toda a trajetória escolar do aluno.
\end{abstract}

Palavras-chave: Psicanálise; Inibição intelectual; Dificuldades de aprendizagem.

Impasses dans l'apprentissage et inhibition intellectuelle: Cet article décrit les résultats d'une rechercheintervention psychanalytique à travers le rapport d'une étude de cas d'un élève dans la primaire d'une école publique de la ville d'Itabira-MG. L'élève fait face à plusieurs obstacles dans l'apprentissage qui entravent son processus d'alphabétisation. L'étude de cas vise à démontrer l'apport d'un méthode d'investigation utilisé dans cette recherche, qui est le diagnostic clinico-pédagogique (DCP), dont l'idée est d'apprendre avec le garçon ce qu'il enseigne à l'éducateur sur sa difficulté et compris les éléments de subjectivité que sont en tant d' interférer dans sa relation avec l'apprentissage. Les résultats obtenus dans la recherche ont permis de percevoir comment l'angoisse de castration, les peurs infantiles et les phobies peuvent être à l'origine de l'inhibition intellectuelle, en compromettant toute la trajectoire scolaire de l'élève.

Mots clés: Psychanalyse; Inhibition intellectuelle; Difficultés d'apprentissage.

\section{Impasses in learning and intellectual inhibition:}

This article describes the results of a psychoanalytic-oriented research-intervention through the report of a case study of an elementary school student at a public school in the state school in the city of Itabira-MG. The student 
faces several obstacles in learning, which hinder his literacy and his literacy process. The aim is to demonstrate the contribution of one of the instruments used in this research, which is the clinical-pedagogical diagnosis (CDP). It's intervention reads what the boy teaches the educator about his subjectivity and how his particularities can interfere in the relationship with knowledge. The results obtained by the research allowed us to perceive how castration anxiety, infantile fears and phobias can constitute the phenomenon of intellectual inhibition and compromise the student's entire school journey.

Keywords: Psychoanalysis; Intellectual inhibition; Learning difficulties. 


\title{
Impasses na aprendizagem e inibição intelectual
}

\author{
Luciana Renata Moreira Fonseca, Raquel Martins de Assis \& Ana Lydia Bezerra Santiago
}

\section{Introdução}

Este artigo apresenta um estudo de caso de César ${ }^{2}$, um menino com 9 anos de idade cursando o 40. ano do ensino fundamental em uma escola pública da cidade de Itabira, no Estado de Minas Gerais, considerada referência em qualidade. Destaca-se um dos procedimentos da pesquisaintervenção psicanalítica proposta pelo Núcleo Interdisciplinar de Pesquisa em Psicanálise e Educação (NIPSE) da Universidade Federal de Minas Gerais (UFMG), utilizados nos casos de entraves na aprendizagem escolar o Diagnóstico Clínico- Pedagógico (DCP). O DCP foi forjado como um método de intervenção inspirado na psicanálise, que visa localizar em qual das duas esferas encontra-se a dificuldade de aprendizagem da criança: na esfera conceitual pedagógica ou na esfera clínica (Santiago, 2011, p. 97)

A análise dos impasses escolares não só sob a ótica da educação, mas também à partir do aporte teórico da psicanálise nos ajuda a pensar e discutir essa problemática com um outro olhar e uma outra escuta. Segundo essa tônica, autores como Kamada; Nascimento (2017), Millot (1995), Cohen; Besset (2002), Mrech (2003), Santiago (2005), Miranda (2006), Miller (1998), Lacan (1999) trazem uma importante contribuição da psicanálise. Já na abordagem pedagógica, Ferreiro \& Teberosky (1999), Silva (2008), Fonseca (2015), Soares (2017 e 2020) são autores que apresentam estudos e pesquisas com destaque para a intervenção do pedagogo, visando modificar a situação do aluno diante das dificuldades de aprendizagem.

O caso que será descrito nesse artigo conta um pouco da história e trajetória escolar de César, um aluno que estudava em uma escola em que foi proposta a pesquisa-intervenção como uma forma de oferecer a ajuda da psicanálise para as crianças que a escola identifica como casos paradigmáticos. Tais casos se referem a alunos em situação de fracasso escolar, que já passaram por diversas estratégias pedagógicas propostas pela escola e se mostraram refratários a todas elas.

César estudava nessa escola desde os 6 anos de idade, mas ainda se encontrava em um nível de escrita condizente com o de uma criança que ainda não estava alfabetizada. Dessa forma, apresentava muita dificuldade para acompanhar as aulas e para realizar as atividades propostas para a turma-série que frequentava. Como será possível perceber, o caso de César mostrou-se especialmente esclarecedor em relação ao problema da inibição intelectual e ao ponto em que a intervenção pedagógica falha nesses casos.

Para os alunos com baixo desempenho essa instituição ofertava atividades que eram nomeadas, como: Programa de Intervenção Pedagógica 1 (PIP1) e Programa de Intervenção Pedagógica 2 (PIP2). O PIP1 consistia em um atendimento mais individualizado que era realizado pelo próprio docente dentro da sala durante as aulas, através de atividades diferenciadas. Já o PIP2 
compreendia os estudos orientados extras. Assim, no PIP2 o(s) aluno(s) recebiam atividades para realizar em casa com o acompanhamento da família. Essas atividades eram corrigidas pelos docentes e devolvidas aos alunos. No PIP2, a única ajuda que a criança recebia era a de sua família. Porém um dificultador dessa proposta é que nem toda a família tem tempo e se sente preparada para auxiliar a criança.

Além do PIP1 e do PIP2, a escola também oferecia o reforço escolar. O reforço era realizado na própria escola e no turno em que o aluno estudava. Outra estratégia que essa instituição adotava era o Projeto Consolidando a alfabetização em sessenta lições. Tal projeto era composto por um planejamento detalhado de sessenta aulas e tinha por finalidade trabalhar a leitura. Cada aula é dividida em cinco momentos cronologicamente definidos:

1. Leitura de deleite: 0 professor deve ler o texto sugerido para aquele dia e explorá-lo oralmente com seus alunos. Esse momento deve durar exatamente 20 minutos.

2. Consciência fonológica: para esse trabalho são propostas atividades que o professor deve desenvolver, dentre elas: trava-línguas, quadrinhas, jogos e brincadeiras. 0 tempo de duração é de 15 minutos.

3. Trabalho com alfabeto: as atividades definidas nesse item têm como propósito ajudar as crianças na identificação e no reconhecimento das letras do alfabeto. Esse momento deve durar 15 minutos.

4. Compreensão da natureza alfabética do sistema de escrita: o trabalho indicado aqui é composto por atividades que envolvem sílabas, rimas e formação de palavras, e deve ser realizado em 20 minutos.

5. Leitura: esse momento é diferente do primeiro, porque é uma leitura com outros objetivos, tais como: o aluno procurar por determinadas palavras em revistas, ler as frases apontadas, localizar algumas palavras em um texto. Essa proposta tem duração de 15 minutos e é seguida pelo encerramento da aula, em que, em 5 minutos o professor pode fazer uma reflexão com os alunos ou uma avaliação rápida daquele dia.

Esse projeto apresenta uma proposta bem sistematizada, com estabelecimento de um cronograma. Ele visa o incentivo à leitura, porém por não apresentar a possibilidade de "criação" por parte do docente, ele pode acabar "engessando" o trabalho pedagógico. Também é importante frisar que embora César não tivesse apresentado nenhum tipo de avanço na aprendizagem, aquele era o segundo ano seguido que o garoto era inserido no projeto.

Nesse sentido, os dispositivos utilizados para a realização da pesquisa-intervenção de orientação psicanalítica propõem isolar e introduzir a subjetividade do aluno, partindo da premissa de que é possível abrir um espaço analítico na escola que difere daquele que é realizado na clínica, mas que também se utiliza das contribuições dessa prática. 
Esse artigo visa apresentar os resultados obtidos à partir do DCP. No entanto faremos menção a dois outros procedimentos que foram utilizados nessa pesquisa: a entrevista clínica de orientação psicanalítica (ECOP) e a conversação. Para apresentar a contribuição pontual da intervenção pedagógica de inspiração psicanalítica, o artigo será discutido em tópicos.

\section{Métodos da pesquisa-intervenção de orientação psicanalítica na instituição escolar}

A utilização da psicanálise de orientação lacaniana, em espaços como o escolar, oferece uma importante contribuição para a área da educação, além de propiciar que seja feita uma leitura do sintoma dessa instituição. Nesse sentido, as intervenções propostas permitem que seja revelado o impasse que o discente vivencia à partir da sua subjetividade e singularidade na relação com o saber, e que repercute no seu desempenho acadêmico e mesmo nas relações com os colegas, professores e outros profissionais presentes no contexto escolar.

As metodologias com orientação psicanalítica que são propostas e realizadas na pesquisaintervenção consistem em: diagnóstico clínico-pedagógico (DCP), entrevista clínica de orientação psicanalítica (ECOP) e na conversação. Tais metodologias permitem uma leitura prévia do sintoma escolar de cada instituição, uma intervenção particularizada com o aluno e uma intervenção com a equipe escolar. O DCP proposto por Santiago (2011)

é um processo de investigação-intervenção que parte da dificuldade da criança com a aprendizagem escolar e visa à identificação circunscrita de seus impasses em duas esferas distintas: (1) conceitual e pedagógica, (2) relativa à subjetividade. Mais precisamente, a esfera conceitual baseia-se na investigação do conhecimento da criança, no plano estrito do seu domínio dos fundamentos para a superação dos erros de conteúdo. A esfera subjetiva é investigação a partir de um método de inspiração clínica, em que a criança é interrogada sobre sua dificuldade, como se interroga alguém sobre seu sintoma. Busca-se esclarecer a trajetória intelectual da criança até o ponto de seu impasse. Considera-se que a criança é quem tem o que dizer sobre sua dificuldade. (Santiago, 2011, p. 97)

Já a ECOP consiste em realizar entrevista com a criança identificada pela escola como um aluno que apresenta impasses na aprendizagem, sendo entrevistados também os pais ou responsáveis, quando isso se faz necessário. Esses dois procedimentos favorecem a construção de um trabalho individualizado, considerando-se a subjetividade do aluno e propondo uma intervenção a partir do que ele vai nos ensinando sobre o que lhe acontece. Assim, no início, (às vezes no decorrer) e no final do trabalho, além das duas metodologias também é utilizada a conversação. A conversação

é uma prática da palavra para tratar manifestações indesejadas que produzem insucessos e fracassos. Busca-se uma mutação do falar livremente sobre os problemas. 0 
ponto de partida para as conversações é "o que não vai bem", formulado por meio das queixas. A aposta das conversações é passar da queixa - que paralisa a ação dos professores e produz identificações indesejáveis para os alunos - a um outro uso da palavra em que a queixa toma a forma de uma questão e a questão, a forma de uma resposta: invenções inéditas. (Santiago, 2011, p. 97).

De acordo com Santiago (2011), as conversações que são realizadas com a equipe escolar (gestores e professores) têm por finalidade promover achados inéditos a partir da circulação da palavra e permitir que algumas identificações sejam desconstruídas. A pesquisa-intervenção inicia-se pela conversação, momento em que é levantado junto às escolas, os alunos que são considerados como um problema. Pode ser necessária a realização de outras conversações durante o trabalho. $\mathrm{E}$, ao final da pesquisa, é feita uma conversação devolutiva, que permite mudanças na posição da equipe escolar em relação aos alunos que foram acompanhados nesse processo.

\section{A história de César e os entraves na aprendizagem}

$\mathrm{Na}$ época da pesquisa, César tinha 9 anos de idade e frequentava o $4^{\circ}$. ano do ensino fundamental. Durante a etapa de análise documental foram encontrados na pasta do aluno, além dos documentos básicos necessários à matrícula, um histórico escolar que assinalava que, apesar de ter um rendimento acadêmico insuficiente, ele havia sido aprovado por progressão continuada, e um relatório pedagógico solicitando uma avaliação médica. No relatório destaca-se o seguinte trecho:

Encontra-se no nível da pseudo leitura e escrita pré-silábica. Na escrita utiliza letra cursiva para copiar o quadro. Apresenta dificuldade para entender conceitos básicos, reconhecer o alfabeto e os números. Não consegue interpretar frases ou pequenos textos. Também apresenta dificuldade em realizar as atividades propostas e em reter o que está sendo ensinado. É necessária a constante intervenção da professora para concluir as atividades propostas. O raciocínio lógico-matemático é abaixo do esperado para a idade e ano que está cursando.

Ressalta-se que, embora esse relatório tenha sido elaborado dois anos antes da nossa pesquisa, observamos que César ainda apresentava os entraves citados no relatório, tendo evoluído apenas no nível de escrita.

Durante a primeira conversação, a escola também relatou que ele não tinha uma boa oralidade e não apresentava uma percepção razoável dos acontecimentos. A escola levantava uma hipótese de problema orgânico que era evidenciado na solicitação de uma avaliação neurológica. A família, por sua vez, não atendia às solicitações da escola e César permanecia sem um diagnóstico 
que pudesse justificar os impasses na aprendizagem e continuava passando pelas mesmas propostas de intervenção pedagógica anos após anos.

Ao conversar com a professora regente percebemos que ela evidenciava os tropeços acadêmicos que comprometem o rendimento escolar do aluno, embora ele não apresentasse nenhum problema em relação ao comportamento:

César é um menino apático... ele praticamente não participa das aulas, devido a falta de conhecimento alfabético. Pode até ser que ele tenha conhecimento de mundo, mas na hora de ler alguma coisa... aí ele fica todo tímido. Eu vejo que ela abaixa muito a cabeça durante as aulas. (pausa). Mas, na sala de aula, eu vejo que ele tenta... ele vai lá na frente e me pergunta: É pra fazer isso aqui? Ele mostra a atividade. Mas a gente sabe que ele não sabe ler... Ele oscila entre a apatia e a vontade de aprender, e é mais a apatia. Em relação à disciplina, não tenho problemas. (Professora regente)

Um aspecto revelado nessa conversa foi a questão da apatia de César. A professora questiona até o conhecimento de mundo do menino, e enfatiza que ele não sabe ler. Já a professora de biblioteca que trabalhava atividades de alfabetização com César e outros alunos nos horários vagos, nos conta:

Quando comecei a trabalhar com César esse ano, a professora do reforço me disse que ele não consegue reter informação. Mas eu não concordo com isso. Ele não conseguia escrever o nome completo, hoje ele consegue. Ele ainda confunde as letras do alfabeto, mas se esforça para aprender (...). Eu estou trabalhando com ele quando tenho tempo, mas não é um trabalho constante, pois sempre falta algum professor, e eu tenho que cobrir a aula. (pausa). Quando posso, utilizo o computador e ele gosta muito. Ele não tinha contato com computador... a família é muito pobre. Sempre leio revistas da turma da Mônica para ele, ele gosta e demonstra entendimento da história. (Professora de Biblioteca).

$\mathrm{Na}$ fala dessa professora percebemos que ela associa as dificuldades de aprendizagem apresentadas por César a uma suposta carência sociocultural. Porém, durante os encontros promovidos pela pesquisa notamos que a família de César se enquadra no perfil de classe média. E a falta de acesso a um computador e a outros recursos não estava ligada aos aspectos econômicos da família. Para explicar os impasses que César apresentava na aprendizagem, a escola e os professores levantavam hipóteses. No entanto, nenhuma dessas hipóteses se confirmou.

\section{O que a mãe de César nos diz}


Durante a ECOP realizada com a mãe de César, que aqui chamaremos de Sra. R., ela nos relata que a família mora em uma casa herdada pelo pai de César. Nessa casa residem César, sua mãe, seu pai, uma irmã de 1 ano e 4 meses, além de uma prima do seu pai, uma mulher cega, e a filha dessa prima, uma jovem com deficiência intelectual. Sendo que o relacionamento entre César e a moça com deficiência intelectual era muito conflitivo.

Segundo a Sra. R, César teve um desenvolvimento normal, andou e falou dentro do tempo esperado, nunca teve problemas com a alimentação. Porém, o sono dele sempre foi muito agitado e permeado por pesadelos. Além disso, o medo sentido pelo menino era grande o suficiente para que ele e a irmã precisassem dormir no quarto dos pais.

Ao ser questionada sobre quantas pessoas da família não sabiam ler e escrever, ela aponta a mãe de seu marido, avó paterna de César, já falecida. Ela também nos contou que César era muito apegado a essa avó que o paparicava muito. E considerando a relação de César com essa avó ela imaginou que o menino sofreria muito e daria trabalho em função de tal morte, porém isso não aconteceu. A Sra. R enfatiza que César ficou bem.

Em relação ao grau de escolaridade, ela nos informa que possui o $2^{\circ}$ grau completo e que 0 seu marido estudou apenas até o $4^{\circ}$ ano do ensino fundamental. Mesmo assim, a Sra. R afirma que o seu marido tem muito mais inteligência e conhecimento do que ela, que ele sustenta a casa e ela nunca trabalhou.

\section{Resultados}

\section{O que César nos diz}

César compareceu pontualmente a todos os encontros da pesquisa, mostrando-se sempre muito interessado e disposto a colaborar. A primeira atividade proposta consistia em disponibilizar vários livros para que César escolhesse um e realizasse sua leitura. César escolheu um livro com a história de um lobisomem. Ele observava as gravuras e ia criando um enredo baseado nessas imagens. Em seguida foi solicitado um desenho. César desenhou uma casa com chaminé e explicou onde ficava cada cômodo. E a última atividade do primeiro dia foi um ditado, conforme o quadro abaixo:

\begin{tabular}{|l|l|}
\hline Produção do aluno & Palavras sorteadas para o ditado \\
\hline ISAEU & BICICLETA \\
\hline QIAE & GALINHA \\
\hline GOA & GATO \\
\hline CAEIOC & CASA \\
\hline OAEO & SOL \\
\hline
\end{tabular}


A análise do ditado nos mostra uma escrita condizente com o nível de um aluno que ainda não está alfabetizado.

No decorrer dos encontros, foi possível perceber o interesse do menino por jogos, sobretudo quebra-cabeças, trilha, jogo da forca, jogo do alfabeto e, principalmente, jogo da memória. Além desses jogos, também realizamos outras atividades que favorecessem a apropriação do princípio alfabético ao mesmo tempo que promovessem o letramento. Como o relatório da escola enfatizava a dificuldade em se lembrar do que aprendeu, foi surpreendente o interesse dele por um jogo da memória, em que era utilizada uma carta com uma imagem, sendo sua correspondente a escrita da palavra.

Ao longo do processo procuramos promover atividades com temáticas que fossem do interesse do menino. $E$ junto com esse trabalho procuramos ouvir o que ele tinha a nos dizer. Então, as conversas com César giravam em torno de personagens que causavam medo. César demonstra especial interesse por histórias de lobisomens, vampiros e bruxas.

$\mathrm{Na}$ aprendizagem, ele tinha avanços e retrocessos. Em alguns dias, apresentava uma escrita alfabética. Como num dia em que escreveu: LOBO - DITADO - BOLA - SAPO. Em outros, não conseguia sequer identificar ou reconhecer letras. $O$ que se mantinha era apenas $O$ interesse por histórias fantasmagóricas.

Ao abrir espaço para se falar livremente sobre o que quisesse, César começou a falar sobre seus medos, citando uma série de TV que ele assistia e contando que seus personagens eram Zumbis. De acordo com ele, Zumbis são "humanos ruins, humanos mortos que mordem pessoas." A referência a temas ligados à devoração de partes do corpo ou mesmo à morte, nos remete à angústia de castração, que é muito comum entre os meninos. Assim da história de Zumbis, César passa ao relato de seus pesadelos:

- "Eu lembro que era só eu, não tinha mais ninguém, estava tudo cheio de sangue. Quando eu abri a porta da minha casa, estava todo mundo morto. Aí eu acordei."

- "Eu sonhei que, quando eu era pequeno, eu, meu pai, minha mãe e minha irmã estávamos caindo."

Nos pesadelos é possível verificar que as situações que se apresentam nunca trazem um desfecho favorável para César. No entanto, é a partir deles que o menino começa a abordar os seus medos, que ele denomina como mal. Segundo César, falar do "mal" não era bom, pois isso poderia fazer com que este aparecesse. Ao ser questionado sobre o mal, ele confidencia que é o bicho que mora debaixo da terra. O menino nos diz que um dia seu pai viu o mal, e que esse era um bicho com olhos vermelhos.

À medida que César falava de seus medos, a inibição intelectual ia cedendo, e ele apresentava discretos avanços na aprendizagem. Os seu pesadelos também começavam a se modificar e ter um final melhor: 
- "Eu, meu pai e minha mãe estávamos procurando minha irmã. Então, nós chegamos em um lugar cheio de fogo e chifre. Aí nós conseguimos resgatar a minha irmã."

Nas entrevistas clínicas de orientação psicanalítica, César também demonstrava seus avanços. O desenho que antes tinha apenas uma casa, ganha novos elementos, como um ladrão que aparece para roubar coisas importantes. Mas, dessa vez, César tinha um segredo, que era a presença da polícia para resolver a situação.

Assim, embora o tema da castração estivesse presente, César começava a criar recursos internos para lidar com seus temores. Vê-se que, mesmo após as intervenções pedagógicas, que trabalhavam a parte conceitual, persistia a necessidade de César "esquecer" o que já tinha aprendido. Dessa forma, fez-se necessário encaminhá-lo para uma análise.

\section{Discussão ou conclusão}

O caso César nos faz refletir sobre a situação de vários alunos que passam por diversas intervenções pedagógicas e continuam apresentando embaraços no seu desempenho acadêmico. Diante desses alunos que desafiam o saber da escola, uma vez que não conseguem avançar na aprendizagem e se mostram refratários às estratégias adotadas pela escola para promover a aprendizagem é feita uma fatídica pergunta: O que esse menino tem? (Santiago; Assis, 2015).

Buscando responder a essa pergunta, a instituição escolar procura em outros campos do saber essa resposta. Desse modo são feitas as solicitações e encaminhamentos de tais alunos para a avaliação médica ou psicológica. A escola começa a levantar hipóteses que possam justificar as dificuldades apresentadas pelas crianças.

No caso de César, além da hipótese de um problema orgânico identificado na solicitação de avaliação neurológica, encontramos também a hipótese do déficit sociocultural que é fundamentada na suposição da professora, que atribui os entraves acadêmicos do aluno a uma possível pobreza que ela acredita que a família passa.

Através do DCP percebemos que as dificuldades apresentadas por César localizam-se na esfera clínica, pois mesmo após trabalhar a parte conceitual, os impasses persistem. A angústia de castração e a fobia se materializaram em uma inibição intelectual. Mas o que é uma inibição? Inibição é um fenômeno em que ocorre a suspensão de uma ação. Assim,

na inibição, o sujeito revela alguma coisa de sua verdade através de um não que é um não de recusa, não é mais o não reproduzido no discurso, é um ato: a parada de pensar é um ato da mesma qualidade que a parada de fazer (anorexia, paralisia). (Cordié, 1996, p. 151). 
Para a psicanálise, um ato é diferente de uma ação, pois o primeiro está ligado ao inconsciente que marca uma repetição. Logo, nesses casos, a dificuldade de aprendizagem possui o estatuto de um sintoma que incomoda e, por isso, pede deciframento (Neves, 2011, p. 154).

Assim é importante se levar em conta a subjetividade da criança e a forma como essa pode estar se refletindo nos embaraços da criança com os conteúdos escolares.

Cohen (2006, p. 92) ressalta que a "recusa em saber muitas vezes aparece na criança como uma impossibilidade de entrar em contato com temas que tocam em pontos delicados do seu ser." No caso de César, percebemos que a angústia de castração e a fobia provocavam uma inibição que se manifestava na aprendizagem. Dessa forma, as intervenções pedagógicas pareciam não surtir efeito, então para os professores e gestores da instituição era difícil definir adequadamente o que acontecia com César. Porém, o diagnóstico clínico-pedagógico nos mostrou que os entraves de César localizavam-se na esfera clínica. Pois, mesmo após oferecer explicação ou orientação relacionada à dificuldade do menino, os tropeços na alfabetização continuavam e se evidenciam através de um movimento marcado por avanços e retrocessos.

Diante disso, ao final do trabalho, César demonstrou uma demanda de análise e foi encaminhado para tal serviço. Também foi indicado um serviço de aula particular para ajudar o aluno a vencer as defasagens acadêmicas.

\section{Notas}

1. Esse artigo foi escrito inicialmente para integrar a dissertação de mestrado intitulada Impasses na aprendizagem e inclusão escolar: estudos de caso sob a ótica da psicanálise (2015), orientada pela professora Dra. Raquel Martins de Assis, e contou com o apoio financeiro e incentivo da FAPEMIG (Fundação de Amparo à Pesquisa do Estado de Minas Gerais). Posteriormente, o texto sofreu modificações e acréscimos para compor um artigo intitulado Dificuldades de Aprendizagem e inibição intelectual: intervenções sob a perspectiva da Psicanálise, que foi publicado no livro: História, memória e práticas da inclusão escolar (2017). Agora sofreu novas modificações e outros acréscimos para compor um artigo desta revista. Atualmente a doutoranda pesquisa os sintomas das crianças e dos adolescentes na contemporaneidade, orientada pela professora Dra. Ana Lydia B. Santiago.

2. Nome fictício adotado no intuito de proteger a identidade do menino.

\section{Referências Bibliográficas}

Cohen, R. H. P.; Besset, V. L. (2002). O fracasso escolar na clínica com crianças e adolescentes: educação entre o impossível e o necessário. Estilos da clínica, v. VII, n. 13, p. 146-157.

Cordié, A. (1996). Os atrasados não existem: psicanálise de crianças com fracasso escolar. In Sônia Flach e Marta d'Agord (trad.). Porto Alegre: Artes Médicas. 
Ferreiro, E.; Teberosky, A. (1999). Psicogênese da língua escrita. In Diana Myriam Lichtenstein, Liana Di Marco e Mário Corso (trad.). Porto Alegre: Artmed.

Fonseca, L. R. M. (2015). Impasses na aprendizagem e inclusão escolar: estudos de caso sob a ótica da Psicanálise. Dissertação de mestado. Faculdade de Educação da Universidade Federal de Minas Gerais (UFMG), Belo Horizonte.

Kamada, M. Y.; Nascimento, L. C. R. (2017, jul-dez) Em busca do conhecimento em educação e psicanálise. PSI UNISC. [on-line], Santa Cruz do Sul, v.1, n.1, p.113-128. Recuperado de http://www.online.unisc.br/seer/index.php/psi/article/view/9607

Lacan, J. (1999). O seminário, livro 5: as formações do inconsciente. Rio de Janeiro: Jorge Zahar.

Miller, J. (2014) . "A criança e a mulher e a mãe". Opção Lacaniana. [on-line], 15. Recuperado de http://www.opcaolacaniana.com.br/nranterior/numero 15/crianca entre mulher mae.p.115.pdf

Millot, C. (1987). Freud Antipedagogo. (Trad. autorizada da primeira edição francesa, publicada por Navarin Éditeur). Jorge Zahar Editor Ltda. Rio de Janeiro.

Miranda, M. P. (2006). Sobre a criança problema e o mal-estar do professor. Dissertação de mestrado. Faculdade de Educação da Universidade Federal de Minas Gerais (UFMG), Belo Horizonte.

Mrech, L. M. (2003). Psicanálise e educação: novos operadores de leitura. São Paulo: Pioneira.

Neves, L. R. ( 2011). Teatro Conversação na escola: o uso do teatro na conversação como mediador de conflitos na educação. Tese de doutorado. Programa de Pós-graduação da Faculdade de Educação da Universidade Federal de Minas Gerais. Belo Horizonte.

Santiago, A. L. B. (2005). A inibição intelectual na psicanálise, Rio de Janeiro: Jorge Zahar Ed.

Santiago, A. L. B. (2011). Entre saúde mental e educação: abordagem clínica e pedagógica de sintomas na escola nomeados por dificuldades de aprendizagem e distúrbios de comportamento. In: SANTIAGO, A. L.; CAMPOS, R. H. F. (Orgs). Educação de crianças e jovens na contemporaneidade: pesquisas sobre sintomas na escola e subjetividade. (p. 93-99). Belo Horizonte: Ed. PUC Minas.

Santiago, A. L. B.; Assis, R. M. (2015). O que esse menino tem? Sobre alunos que não aprendem e a intervenção da psicanálise na escola. Belo Horizonte, Editora Sintoma.

Silva, M. M. M. (2006.) "Os alunos da sala 11". Presença pedagógica. Vol.12(72), p. 16-33. Ed. Dimensão.

Soares, M. (2017). Alfabetização: a questão dos métodos. São Paulo: Contexto.

Soares, M. (2020). Alfaletrar: toda criança pode aprender a ler e a escrever. São Paulo: Contexto. 
Citação/Citation: Moreira Fonseca, L.R., Martins de Assis, R., Bezerra Santiago, A.L. (nov. 2020 a abr. 2021). Impasses na aprendizagem e inibição intelectual. Revista aSEPHallus de Orientação Lacaniana, 16(31), 40-51. Disponível em www.isepol.com/asephallus. Doi: 10.17852/1809-709x.2021v16n31p40-51

Editor do artigo: Tania Coelho dos Santos.

Recebido/Received: 10/03/2020 / 03/10/2020.

Aceito/Accepted: 10/28/2020 / 28/10/2020.

Copyright: (c) 2019 Associação Núcleo Sephora de Pesquisa sobre o moderno e o contemporâneo. Este é um artigo de livre acesso, que permite uso irrestrito, distribuição e reprodução em qualquer meio, desde que o autor e a fonte sejam citados/This is an open-access article, which permites unrestricted use, distribution, and reproduction in any medium, provided the author and source are credited. 